\section{Generalized kappa coefficient: A Microsoft BASIC program}

\author{
JOHAN H. OUD \\ University of Nijmegen, Nigmegen, The Netherlands \\ and

\section{JEROME M. SATTLER \\ San Diego State University, San Diego, California}

The kappa coefficient is designed to measure nominal rating agreement among observers (or raters). The program presented here is based on Uebersax's (1982) formula, which is a generalized method for computing kappa that can be used for multiple observers (or raters) and multiple categories and that takes into account missing data as well. Previous programs for computer applications of kappa have not been designed to handle these features (Berk \& Campbell, 1976; Bloor, 1983; Burns \& Cavallaro, 1982; Watkins \& Larimer, 1980; Wixon, 1979).

The program allows for up to 500 subjects (or intervals), 10 observers, and 15 categories. Values can be increased or decreased to accommodate computers with varying degrees of storage capacity.

Input. Initial inputs are the number of subjects (or observation intervals) and the number of observers (or raters). The program then requests the category number (or score) for each subject and each observer. The user has the option of correcting any entry and of requesting kappa for any combination of observers. The data are stored and can be reused in new runs of the program.

Output. The output consists of the observed propor-

The authors' mailing addresses are: J. Oud, Katholieke Universiteit, Instituut voor Orthopedagogiek, Erasmusplein 1, 6500 HD Nijmegen, The Netherlands; J. M. Sattler, Department of Psychology, San Diego State University, San Diego, CA 92182. tion of agreement (PO), the chance proportion of agreement $(\mathrm{PE})$, and kappa $=(\mathrm{PO}-\mathrm{PE}) /(1-\mathrm{PE})$ across all raters. When requested by the user, the program provides the same information for any desired combination of observers. For two observers and no missing data, the program also automatically provides the approximate standard normal test $\mathrm{z}$ statistic, the standard error, and the $95 \%$ confidence interval of kappa.

Limitations. The total amount of memory required is determined by the number of subjects, observers, and categories. Without modification, the program requires 30K RAM.

Language and Computer. The program is written in Microsoft BASIC and can be used with the IBM PC and Apple II microcomputers.

Availability. A program listing is available at no charge from Johan Oud, Katholieke Universiteit, Instituut voor Orthopedagogiek, Erasmusplein 1, 6500 HD Nijmegen, The Netherlands.

\section{REFERENCES}

Berk, R. A., \& CAMPbell, K. L. (1976). A FORTRAN program for Cohen's kappa coefficient of observer agreement. Behavior Research Methods \& Instrumentation, 8, 396.

BLooR, R. N. (1983). A comptuer program to determine interrater reliability for dichotomous-ordinal rating scales. Behavior Research Methods \& Instrumentation, 15, 615.

Burns, E., \& Cavallaro, C. (1982). A computer program to determine interobserver reliability statistics. Behavior Research Methods \& Instrumentation, 14, 42.

UEBerSAX, J. S. (1982). A generalized kappa coefficient. Educational and Psychological Measurement, 42, 181-183.

WATKINS, M. W., \& LARIMER, L. D. (1980). Interrater agreement statistics with the microcomputer. Behavior Research Methods \& Instrumentation, 12, 466.

WIXoN, D. R. (1979). Cohen's kappa coefficient of observer agreement: A BASIC program for minicomputers. Behavior Research Methods \& Instrumentation, 11, 602 .

(Revision accepted for publication October 27, 1984.) 